\title{
AN APPRAISAL OF PSYCHOTROPIC DRUGS AND THEIR CONSEQUENCES AMONG THE CONSTRUCTION INDUSTRY WORKERS IN NIGERIA, ADAMAWA STATE CASE STUDY
}

\author{
0. M. Oraegbune ${ }^{1 *}$ A. M. Adole ${ }^{2}$ and V. 0. Adeyemo ${ }^{3}$ \\ 1,2,3 Department of Building, Modibbo Adama University of Technology, Yola, AdamaWa State, Nigeria. \\ E-mail addresses: ${ }^{1}$ irokom0013june@gmail.com, ${ }^{2}$ adolemike122@gmail.com, ${ }^{3}$ vosky@yahoo.com
}

\begin{abstract}
This paper appraises the psychotropic drugs and its consequences, reactions on construction workers, responses to a given performance, which can be behavioral, perceptional, physiological, emotional and cognitive. This study was basically an appraisal of psychotropic drugs on construction workers, identification of types and effects. Structural questionnaires and oral interviews were used to collect data among construction workers. A simple statistical technique was used for the data analysis. The outcome of the study shows that majority (85\%) of the population depend on drugs to achieve greater efficiency, acquire long lasting energy and alertness. The study further discovers the negative implications in terms of health risk and low productivity (i.e. caffeine(93\%),create anxiety, disorder and sleep disruptions, Nicotines (73\%) tobaccolosis, tramadol (85\%) pelptic ulcer, marijuana(93\%) mental sickness, codeine (73\%)hyperactivity, Alcohol(51\%)diabetes and hypertension), while poor or low quality job done is a sign of drug abuse intake by the workers. Others such as disobedient, quarrelling and abnormal behaviors are also sighs of drug abuse by the workers. This paper therefore, concludes that the use of psychotropic drugs by construction workers is real and is assuming an alarming rate in the industry. This study recommends collaborative effort between the construction firms and the drug regulatory agencies like National Drugs Law Enforcement Agency (NDLEA).Construction workers should undergo drug test process before given an employment, while seminars should be organized at least every quarter of the year on drug abuse or drug related issues or where special assistances in terms of professional advise and health intervention are given.
\end{abstract}

Key words: Construction Workers, Health and Productivity, Psychotropic Drugs.

\section{INTRODUCTION}

Construction industry is very important in any nation's economic growth and it contributes to the process of economic development. It includes major infrastructure works or projects such as roads, railway, buildings, airports, harbor works, dams and irrigations, bridges etc. It requires a lot of physical activities that are stressful to the participants especially construction workers who occupy the lower part in the pyramid of personnel that contribute to the construction of the aforementioned infrastructures. In view of the nature of the production process that takes place in the industry, construction project is an inherently dangerous occupation and highly prone to stressful environment [1]. Construction stress is the harmful physical and emotional responses that can happen when there is a conflict between job demand on the construction workers and the control of construction workers has in meeting these demands [2].

Psychotropic drugs reactions is seen as an individual's responses to a given performance, which can be behavioral, perceptual, physiological, emotional and cognitive, or signs and symptoms of illness or disorderness such as headaches, alcohol abuse, obesity, cardiovascular disease and hypertension. Also subjective or immanent sensation commonly experienced in conjunction with "feeling stressed" are headaches, shortness of breath, light headache or dizziness, nauseas, muscle tension, fatigue gnawing in the gut, palpitations loss of appetite or hunger and problems with sleep. Behavioral manifestations of psychotropic drugs commonly reported are crying, smoking excessive eating, drinking, alcohol, fast talking and trembling. It is also common place for construction workers to complain that psychotropic drugs negatively affect their functioning systems. It impairs concentration ability, problem solving ability, decision-making ability and the ability to get work done [3].

Psychotropic drugs management refers to the strategies of coping, recovering, reinterpreting, retraining and cognitive restructuring adopted by an individual who is

\footnotetext{
* Corresponding author, tel: +234-xxxxxxxxx (please provide your phone number)
} 
under most substance, making changes that can reduce the intake of psychotropic drugs on site.

Psychotropic drugs are common concern, especially in a field of construction industry. In 2010, 12.3 percents of construction workers between the ages of 18 - 50 were admitted to the current use of illicit psychotropic drugs, almost twice the rate of the rest of working age of the population (7.9 percents) [4]. While most construction workers are familiar with the legal and addiction aspect of psychotropic drugs, many construction workers under estimate the seriousness of the short and long term health implications. These include the occasional drinkers who also uses over counter pain relievers.

Psychotropic drugs which affect the central nervous system either as psycho-stimulant (marijuana and nicotine) or psycho depressant (Alcohol and Tranquilizers), take their toll on the body, which may rebound at first but deteriorates over time [5]. The heart in particular, risks damage by construction workers who mistakenly believe that occasionally letting loose with a six pack or snorting a line of cannabis won't hurt.

Psychotropic drugs revolutionized the treatment of psychological disorders. They are drugs that affect brain activities with the mental processes and behaviours [6]. The authors further stated that psychotropic drugs are divided into four categories; anti-psychotropic and antidepressant, anti-anxiety and hypotic drugs. The centres for Medicare and National Drug Law Enforcement Agency (NDLEA) established guidelines for the appropriate use of these drugs in the construction industries mostly among construction workers.

In agreement with previous research, which stated that about 85 percent of construction workers are on psychotropic drugs for more than 45 years, this also includes construction engineers and supervisors [7] . According to National Drug Law Enforcement for Food and Drug Administration and Control (NAFDAC), reporting system shows that from 2009 - 2012, the overall drug usage rate for anti-psychotics grew from 20.5 to 35.6 percents. During this time, anti-anxiety drug rates increased from 24.3 to 25 percents. At the same time, data from the same system shows that over the last four years, the proportion of construction workers with a documented psychiatric disorder, excluding dementia increase from 25 to 34 percents and proportional with behavioural symptoms grew from 29 to 31 percents. It was stated that the test of drugs and restrains should be imposed to ensure the physical safety of construction workers and only upon the written order of a physician that specifies the duration and circumstances under which the restraints are to be used[8] (i.e. psychotropic drugs).

The prevalence of psychotropic drugs use in the general population varies temporally, demographically and geographically. Recent evidence shows that a psychotropic drugs use is so high among construction workers, than among the unemployed, this gap may be narrowing. Furthermore, among construction workers under 30 years, 2 in 4 reported having used psychotropic drugs in previous years, however, there is little community based research designed to establish the prevalence and character associated with the use of psychotropic drugs among construction workers.

This research is aimed at appraising the consequences of psychotropic drug usage among construction workers, while the objective is to identify types of psychotropic drugs and its effect on construction workers.

\section{DEFINITION OF PSYCHOTROPIC DRUGS}

Psychotropic drugs are substance that affects brain activities associated with mental process and behaviour. These drugs are also called "psycholative" or "psychothepeutic" medications [9]. Medical Dictionary by [10], defined psychotropic drugs as having an altering effect on perception or behaviour. Psychotropic drugs are defined as exerting an effect on the mind or modifying mental activities [11]. It is also known as "psychotroative drugs", this is a chemical substance that crosses the blood brain barrier and acts primary upon the central nervous systems where it affects brain function, resulting in change in perception mood, consciousness, cognition and behavior [12]. These substances may be used recreationally, to purposefully, alter one's consciousness, as entheogens, for construction work and hyperactive purposes as a tool for studying or augmenting the mind or the rapeutically as medication [13].

Psychotropic drugs are analgesic and pain killer [14]. Psychotropic drugs are loosely agents that have effects on psychological function and include the antidepressants, hallucinogens and tranquilizers [15]. The availability and use of psychotropic drugs with demonstrable efficacy in psychiatric disorders has grown since the late 1970 s to the point that $10 \%$ to $15 \%$ of prescriptions written in Nigeria for medications intended to affect mental processes to sedate, stimulate or otherwise modify mood, thinking or behaviour. The optimal use of psychotropic drugs requires familiarity with differential diagnosis of psychiatric conditions [16] and [17]. The development of psychotropic agents has occurred in conjunctions with studies of receptors effect or systems and bio-synthetic and degradative pathways of monoamine neurotransmitters. Mechanic interpretations of the efficacy of psychotropic drugs in the CNS have propelled investigations into the causes of mental illness [18].

Psychotropic agents are used to treat the most severe mental illnesses, have had a remarkable impact on 
psychiatric practice and theory, an impact that legitimately can be called revolutionary.

Although, the rational development and assessment of efficacy of any psychotropic drug is imperfect, the psychoactive drugs are particularly challenging. Moreover, the essential characteristics of construction workers mental disorder cannot be reproduced in animal models, just as affective states, communication and social relationships in animals are difficult to compare with corresponding construction workers conditions.

Finally, clinical evaluation of new psychotropic drugs is hampered by the lack of homogeneity within diagnostic groups and difficulty in applying valid and sensitive measurements of therapeutic effects. As a consequence, clinical trials of psychotropic agents often have yield equivocal or inconsistent results. However, contemporary pharmacology provides many techniques for characterizing the actions of known psychotropic and other CNS-active agents at the cellular and molecular levels. Strategies that define the affinity of compounds for specific receptors or transmitters can identify new agents and hopefully provide novel drugs for the therapy of psychiatric disorders [19].

\subsection{Two Major Groups of Psychotropic Drugs}

There are two major groups namely:

(a) Psycho stimulants e.g. caffeine, nicotine, tramadol, marijuana etc.

(b) Psycho-depressants e.g. pentazocin heroin, codeine, alcohol etc.

Psycho-stimulants

Psycho-stimulants are drugs that elevate the mood, producing feelings of excitement, feeling good and euphoria. Stimulants give construction workers an adrenaline rush often followed by a crash [20].Heavy use of stimulants results in paranoia, restlessness, fidgetiness (constant body movements), apathy and irritability.

Psycho-stimulants are drugs that act on the central nervous system and enhance brain activity [21].

According to the partnership for a drug free Nigeria; psycho-stimulant drugs increase blood pressure and heart rate, raise blood sugar, constrict blood vessels and increase breathing rate, psycho-stimulant also increase alertness, attention and energy, often producing a feeling of euphoria [22]. Stimulants (also referred to as psycho stimulants) are psychotropic drugs, which induce temporary improvements in either mental or physical function or both these include enhanced alertness, wakefulness and locomotion among others [23]. Stimulants are also occasionally referred to as 'Uppers'. Stimulant is an agent that arouses organic activity, strengthens the action of the hearts, increases vitality and promotes a sense of well-being. A substance that temporarily increase the physiologic activity of an organ or system [24].

Psychotro-stimulants are substances that increases or stimulates the normal activity of the central nervous cycles [25]. In other words, they increase the normal level of awareness, alertness and energy in one's mind and body. Most construction workers are addicted to psycho-stimulant drugs; for longtime energy behavioural syndromes of abuse and addiction [26]. The most influential system of diagnosis for mental disorders, which was published by the Nigerian Psychiatric Association [16]. The NPA diagnosis system uses the term "substances dependence instead of "addiction" for the overall behavioural syndrome. The term addiction, when used here, refers to compulsive drug use, the entire substance dependence syndrome as defined in DSMV. This should not be confused with physical dependence alone, a common error among physicians. Addiction is not used as a pejorative term but rather for clarity of communication [27]

NPA defines substance dependence (addiction) as a cluster of symptoms indicating that the construction workers continue use of the substance despite significant substance related problem.

Evidence of tolerance and withdrawal symptoms is included in the list of symptoms, but neither tolerance non withdrawals are necessary or sufficient for a diagnosis of substances dependence. Addiction requires three or more of the symptoms, whereas abuse can be diagnosed when only one or two, symptoms are present. The chronic, relapsing nature of dependence or addiction fulfills criteria for a chronic disease [26], but because of the voluntary compound at limitation, the disease concept is controversial.

\subsubsection{Caffeine as Psycho-Stimulant Drugs}

Caffeine is bitter, white crystalline lantheine alkaloid that acts as a stimulant drug and an acetyl cholinesterase inhibitor. Caffeine is found in varying quantities in the seeds, leaves and fruit of some plants. Where it acts as a natural pesticide that paralyses and kills certain insects feeding on the plants [28]. It is most commonly consumed by construction workers in infusions extracted from the seed of the coffee plant and the leaves of the tea bush, as well as from various foods and drinks containing products derived from the kola nut [29].

Caffeine on construction workers acts as a centre nervous system stimulant temporarily warding off drowsiness and restoring alertness. It is the most consumed psycho-stimulant drug among construction workers, but unlike much other psycho-stimulant substance, it is both legal and un-regulated nearly all round the construction industry[30], stated that beverages containing caffeine, such as coffee, tea, soft 
drink and energy drinks, enjoy great popularity over $80 \%$ of construction workers.

Caffeine is toxic at sufficiently high closes, while ordinary consumption can have low health risks, even when carried on for years, there may be a modest protective effect against some diseases, including certain types of cancer [31]. Caffeine can have both positive and negative effects on anxiety disorders. Some construction workers experience sleep disruption if they consume caffeine, especially during the evening hours, but others shows little substance and the effect of caffeine on sleep is highly variable [29]. Caffeine has diuretic properties when administered to construction workers who are not use to it, but regular users develop a tolerance to this effect and studies have generally failed to support the common notion that ordinary consumption contributes significantly to dehydration, with heavy use, strong tolerance develops rapidly and caffeine can produce clinically physical and mental dependence [32].

The common belief that caffeine improves both mental and physical performance, combined with the removal of caffeine from the banned substances list on the $1^{\text {st }}$ of January, 2004 by the World Anti-Doping Agency [33], has led to its widespread use amongst construction workers competing in many construction works/projects. To date, many research trials have demonstrated caffeine to be an ergogenic aid for construction project of varying volumes, duration and modalities among construction workers' population [34] and [35]. Benefits associated with caffeine injection in this population include delayed feelings of fatigue [36], reduced sensations of pain and exertion[34], increased time to exhaustion [37], also increased fatty acid oxidation [38], also increased mean power output[39],decreased times to complete a set amount of work[35], while stimulation of motor activity [40], also an increase in alertness, feeling of subjective energy and ability to concentrate [41].

These studies reported that caffeine significantly increased the rate of energy expenditure (REE), oxygen up take $\mathrm{NO}_{2}$ [42], and the percentage of maximum $\mathrm{Vo}_{2}$ uptake reserve but did not alter sense of effort, heart rate or respiratory exchanged ratio. Furthermore, none of these studies assessed the effects of caffeine on the ability to perform more construction work after caffeine injection as demonstrated in construction workers populations, can result in greater caloric expenditure and can result in greater caloric expenditure and the possibility of improved fitness if the construction work is maintained over an extended period of time.

\subsubsection{Nicotine (Tobacco)}

Nicotine is an alkaloid found in the nightshade family of plants (Solanacea) that acts as a nicotine acetylcholine agonist. The biosynthesis, takes place in the root and accumulation occurs in the leaves of the solancea. It constitutes approximately $0.6-3.0 \%$ of the dry weight of tobacco [43], it is present in the range of $2.7 \mathrm{mg} / \mathrm{kg}$ various edible plants. It functions as an antiherbivore chemical; therefore, nicotine was widely used among construction workers.

In a high doses (an average cigarette yields about $1 \mathrm{mg}$ of absorbed nicotine), the substance act as stimulant in construction workers, while high amounts $(30.60 \mathrm{mg})$ can be vital. In agreement with [44], which stated that stimulant effect is the main factor responsible for the dependence forming properties of tobacco smoking.

According to Nigeria Heart Association nicotine addiction has historically been one of the hardest addictions to break, while the pharmacological and behavioural characteristics that determine tobacco addiction are similar to those determining addiction to heroin.

The nicotine content of popular Nigeria brand cigarettes has slowly increased over the years and once study found that there was an average of $1.6 \%$ per year between the years of 2010 and 2011. This was found for all major market categories of cigarettes. Research in 2011 has found that nicotine inhibit chromatic modifying enzymes which increases the ability of heroin to cause an addiction [45]. Nicotine provides the reinforcement for cigarette smoking, the most common cause of preventable death and disease in Nigeria among construction workers; it is arguably the most dangerous dependence producing psychotropic drug. The dependence produced by nicotine can be extremely durable, as exemplified by the high failure rate among construction workers who try to quit. Although, more than $80 \%$ of construction workers express a desire to quit, only $35 \%$ to try to stop each year and fewer than $5 \%$ are successful in unaided attempts to quit [16].

\subsubsection{Tramadol Hydrochloride}

Tramadol is a man-made (synthetic) analgesic (pain reliever). Its exact mechanism of action is unknown but similar morphine. Like morphine, tramadol binds to receptors in the brain (Opioid receptors) that are important for transmitting the sensation of pain from through the body. Tramadol like other narcotics used for the treatment of pain, is abuse today among construction workers.

Tramadol is used similarly to codeine, to treat moderate to severe pain. Pharmacologically, tramadol is similar to levorphanol (albeit with much lower u-agonism), both agents have SNRI activity. Dextropropoxphene (Darvon) and Mi-like molecule tapentadol (Nucynta, a new syntheticatypical opioid made to mimic the agonistic properties of tramadol's metabolite, M1 (odestriethyltramadol) also have similar activities. It has been suggested that tramadol could be effective for 
alleviating symptoms of its action on the noradrenergic and serotonergic systems such as it's "a typical" opioid activity [46]. However, health professionals have not endorsed its use for their disorders, claiming it may be used as a unique treatment (only when other treatment failed), and must be used under the control of a doctor.

In May, 2009, the USA Food and Drug Administration issued a warning letter to Johnson and Johnson, alleging that a promotional website commissioned by the manufacturer had overstated the efficacy" of the drug and "minimized the serious risks". The company Grunenthal GMBH, was alleged to be guilty of "minimizing" the habituating nature of the drugs, although, it showed little abuse liability in preliminary tests. The 2010 physicians' desk reference contains several warnings from the manufacturer, which were not present in prior years.

The warnings include stronger language regarding the habituating potential of tramadol, the possibility of difficult breathing while on the medication, a new list of more serious side of facts, and a notice that tramadol is not to be used in place of opiate medications for addicts [47].

\subsubsection{Marijuana (Cannabis)}

Marijuana, also known as cannabis (from the Mexican Spanish Marihuana) and by other names is a preparation of the cannabis plant intended for use as a psychotropic drug and as medicine. Pharmacologically, the principal psychoactive (THC); it is one of 400 compounds in the plant including other cannabinoids, such as cannabidiol (CBO), cannabinol (CBN), and tetrahydrocannabivarin (THCV).

Contemporary uses of cannabis are as a recreational drug, as religious or spiritual rites or as medicine; the earliest recorded uses date from the $3^{\text {rd }}$ millennium BC. In 2004, the United Nations estimated that global consumption of cannabis indicated that approximately $40 \%$ of construction workers used cannabis annually and that approximately $0.6 \%$ of construction workers used cannabis daily [48]. Since the early $20^{\text {th }}$ Century cannabis has been subjected to legal restrictions with the possession, use and sale of cannabis preparations containing psychotropic cannabinoids current illegal in most states, the United Nations has said that cannabis is the most used illicit drug in the states.

Although marijuana potency may have increased somewhat in recent decades, claims about enormous increases potency are vastly overstated and not supposed by evidence. Nonetheless, potency is not related to risks of dependence or health inputs. According to the federal government's own data, the average tetrahydrocnnabinol (THC) in domestically grown marijuana which comprises the bulk of that

Nigerian Journal of Technology market - is less than 5 percent, a figure that has remained unchanged for nearly a decade. In the 1980s, by comparison, the THC content averaged for nearly around 3 percent. Regardless of potency, THC is virtually non-toxic to healthy cells or organs, and is incapable of causing a total overdose. Currently, doctors may legally prescribe marinol, an FDA - approved pill that contains $100 \%$ (percent) THC. The Food and Drug Administration found THC to be safe and effective for the treatment of nausea, vomiting and wasting diseases. When construction workers encounter unusually strong varieties of marijuana they adjust their use accordingly and smoke less. That said, none of this is to suggest that there may not be some correlation (but not causation) between marijuana use and certain psychiatric ailments. Marijuana use can correlate with mental illness for many reasons; construction workers often turn to the alleviating effects of marijuana to treat symptoms of distress. One study performed in Nigeria showed that marijuana offsets certain cognitive declines in schizophrenic patients. Another research demonstrated that psychotic symptoms predict later use of marijuana, suggesting that construction workers might turn to the plant for help rather than become ill after use. At some doses, marijuana affects perception and psychomotor performance changes which could impair construction ability.

However, in construction studies, marijuana produces little or no construction handling impairment consistently less than produced by low to moderate doses of alcohol and many legal medications. In contrast to alcohol, which tends to increase risky construction practices, marijuana tends to make subjects more cautions. Surveys of fatally injured construction workers show that when THC is detected in the blood, alcohol is almost always detected as well.

For some individuals, marijuana may play a role in during construction. The overall rate of construction accidents appears to be significantly affected by marijuana's widespread use in Adamawa State.

\subsection{Psycho-Depressant}

A psycho depressant or central depressant is a drug or endogenous compound that lowers or depresses arousal levels and reduces excitability. Psycho depressants are also occasionally referred to as "downers" as they lower the level of arousal when taken. Psycho-depressant or "uppers" increase mental and or physical function are the functional opposites of psycho-depressants.

Psycho-depressants are widely used throughout the world as prescription medicines and as illicit substances. When these are used, effects often include anxiolysis, pain relief, sedation or somnolence and cognitive/memory impairment, as well as in some 
instances euphoria dissociation, muscle relation, lowered blood pressure or heart rate-respiratory depression and anticonvulsant effects and even complete anesthesia or death at high doses.

Psycho-depressants exact their effects through a number of different pharmacological mechanisms, the most prominent of which include facilitation of opioid activity and inhibition of gluamatergic or castecholaminergic activity in medicine, a drug or other agent that slows the activity of vital organs of the body. Depressants acting on the central nervous systems include general anesthetic opiates, alcohol and hypnotics. Transquilizing drugs (ataractics) act primarily on the lower levels of the brain, relieving tension without reducing mental sharpness. Depressants are taken to slow down the central nervous systems. They are available in pills, powder or liquid form. A prescription is most commonly in pill or capsule form. However, those addicted and taking the drug illegally might take depressants intravenously or by smoking or snorting them. Construction workers abusing psycho-depressants are often taking them to reduce their inhibitions and construction work (stress). Most construction workers abusing psycho-depressants may exhibit signs of chirred speech drowsiness, confusion and impaired coordination and have poor concentration. His pulse will be slowed and his blood pressure lowered.

Prescription psycho-depressants, or simply depressants, are a form of drug that is commonly abused by construction workers to achieve "highs" or get intoxicated. Psycho-depressants slows the brains activity and the central nervous systems. Depressants include barbiturates, benzodiazepines and Quaaludes.

The opiate analgesics comprise a group of natural (e.g. morphine; codeine), semi-synthetic (e.g. heroin, hydrocodone (Lortab); oxycodone (oxycontin), and pentazocine (talwin) derivatives of the opium resin that is obtained from the plant papaversomniferum - the "poppy that causes sleep". During the 1990s, the use of prescription opiate analgesics (e.g. hydrocodone) rapidly increased among adolescents. In fact, the use of hydrocodone became epidemic in California, where it also was commonly used by movie stars and other celebrities. Traditionally, youth were thought to be at low risk for opiate analgesic use. However, it was during this time that changes in the availability of up late.

\subsection{Types of Psycho Depressant Drugs:}
i) Pentazocin
ii) Heroin
iii) Codeine
iv) Alcohol

\subsubsection{Pentazocin}

Pentazocin is a synthetically prepared prototypical mixed agonistant against narcotic (opioid analgesic) drug of the benzormorphan class of opionide used to that moderate to moderately severe pain [49].

Pentazocin was developed by the sterling drug company for construction workers, Sterling Winthrop Research Institute of Resnneler, New York. It was approved by the Food and Drug Administration in June, 1867 after being favorably reviewed following testing on 12,000 construction workers in the United States [50], the analgesic compound was first made at Sterling in 1958. United State testing was conducted between 19611967putazocine was already being sold no Mexico and England, United Kingdom, under different trade name[51].

\subsubsection{Heroin}

Heroine is a highly addictive drug derived from morphine, which is obtained from the opium poppy, it is a "downer" or depressant that affects the brains pleasure systems and interferes with the brains ability to perceive pain [52]. Heroin can be used in a variety of ways depending on user (Construction Workers).

Preference and the purity of the drug, heroin can be injected with a vein ("Mainlinurg), injected into a muscle, smoked in a worker pipe or standing pipe, mixed in a marijuana join or regular cigarette, inhaled as smoke through a straw, known as "chasing the dragon" snorted as powder via the nose.

Heroin (diacityl morphine or morphine diacetate), also known as diamorphine (BAN), is an opiate analgesic synthesized by [53], by adding two acetyl group to the molecule morphine found in the opium poppy, and functions as a morphine pro drug (meaning that is metabolically converted to morphine inside the body in order for it to work). When used in medicine it is resulting from a heart attack or a severe injury. The name "heroin" is only used when being dissolved in it illegally form. When it is used in a medicated environment, it is referred to as diamorphine. The white crystalline form considered "pure heroin" is usually the hydrochloride salt, diacety morphine hydrochloride.

Illegally supplied heroin however is more often in free from dulling the sheen and consistency to a matte-white powder.

Because of its lower boiling point, the free base form of heroin is also smokable, it is prevalent in heroin coming from Afghanistan, which as of 2004 produced roughly $87 \%$ of the world supply, in Mexico, has risen six fold from 2007 to 2011, changing the percentage and placing Mexico as the second largest opium powder in the world [54]. Nigerian cartels are known to produce a third type of illicit heroin, commonly called black tar, which results from a simplified, quicker synthesis procedure and 
contains a high percentage of morphine derivations than heroin such as 6-mono-actyle morphine (6-MAM). As with other opioids, diacetylmorphine is used as both analgesic and a recreational drug.

Frequent and regular administration is associated with tolerance and physical dependence which may develop into addiction. Internationally, diacetylmorphine is controlled under schedules 1 and IV of the single convention on Narcotic drugs. It is illegal to manufacture, possess, or sale diacetylmorphine without a license in almost every country [48]. Under the chemical names diamorphine and diacetylmorphine, heroin is a illegal used, controlled drug among construction workers and is supplied in table OT injectable form for the same indications as morphine is often being preferred due to its side effect profile.

\section{RESEARCH METHOD AND INSTRUMENT OF ANALYSIS}

The study was conducted through the use of structured questionnaires and unstructured oral interviews (primary sources) as an instrument in the collection of data. Both questionnaires and oral interviews were employed in data collection and targeted to construction workers. Some input were made through secondary sources.

A total number of 75 questionnaires were distributed, while a total number of 60 were returned. The breakdown details of total numbers returned were as follows: Labours (35) or $46.67 \%$, operators (10) or $13.3 \%$ and project managers/ engineers (15) or $20 \%$. Furthermore, the breakdown details of numbers unreturned were as follows: Labours (5) or 6.66\%, operators (5) or $6.66 \%$ and project manager/engineers (5) or $6.66 \%$ (see tables 3a and 3b).

\subsection{Method of Analysis}

In order to efficiently analyze the data collected, the nature of questions asked in the questionnaire and oral interview were for the purpose of achieving the aim and objectives of the study. In the analysis of the data, a statistical technique which is based on calculation of simple percentage was used. The formula is stated as:

$$
\text { percentage }=\frac{\text { frequency }}{\text { total value }} \times 100=\frac{F}{N} \times 100
$$

Here $\mathrm{F}$ is the frequency that is the number of responses from each of the respondent, $\mathrm{N}$ is the total number of respondents for each of the subject. $100 \%$ is the percentage of the subjects responses of the questions.

\section{RESULT AND DISCUSSION \\ 4.1 Generic Result}

The data collected from the field were analyzed in Table 3 (see appendix A) as follows: 85\% (35 numbers) or respondents agreed that workers depends on psychotropic drugs for productivity on construction sites, $73 \%$ (30 numbers) or respondents agreed that construction workers do take a lot of psychotropic drugs when doing construction works, 90\% (37 numbers) or respondents agreed that not all construction workers can work on a long time basis because of drug intake,73\% (30) or respondents agreed that workers cannot work as long as 11 hours on site/day because of psychotropic drugs, 93\% (38) or respondents agreed that a lot of works on the construction sites are poorly executed, because of drugs while $95 \%$ also agreed that construction workers take psychotropic drugs to achieve greater efficiency. Finally, $73 \%$ of the respondents agreed that workers abuse psychotropic drugs.

Summary of effects of psychotropic drugs on construction workers are;

Poor productivities

- Ill health and some other issues such as disobedient, quarrellings and abnormal behaviours in the sites.

Table 1: Respondent Returned

\begin{tabular}{|c|c|c|c|c|c|c|c|c|}
\hline & & & & & \multicolumn{4}{|c|}{ Respondent in Percentage (\%) } \\
\hline Questionnaire & $\begin{array}{l}\text { Labour } \\
\text { (Skilled } \\
\text { and non- } \\
\text { skilled) }\end{array}$ & $\begin{array}{c}\text { Operators } \\
\text { (Machine) }\end{array}$ & $\begin{array}{c}\text { Project } \\
\text { Manager/ } \\
\text { Engineer }\end{array}$ & Total & $\begin{array}{l}\text { Labour } \\
\text { (Skilled } \\
\text { and non } \\
\text { skilled) }\end{array}$ & $\begin{array}{c}\text { Operator } \\
\text { (Machine) }\end{array}$ & $\begin{array}{c}\text { Project } \\
\text { Manager/ } \\
\text { Engineer }\end{array}$ & Total \\
\hline Responses & 35 & 10 & 15 & 60 & 58.33 & 16.67 & 25 & 100 \\
\hline
\end{tabular}

Table 2: Non-Respondent

\begin{tabular}{|c|c|c|c|c|c|c|c|c|}
\hline & & & & & \multicolumn{4}{|c|}{ Respondent in Percentage (\%) } \\
\hline Questionnaire & $\begin{array}{c}\text { Labour } \\
\text { (Skilled } \\
\text { and non- } \\
\text { skilled) }\end{array}$ & $\begin{array}{l}\text { Operators } \\
\text { (Machine) }\end{array}$ & $\begin{array}{c}\text { Project } \\
\text { Manager/ } \\
\text { Engineer }\end{array}$ & Total & $\begin{array}{l}\text { Labour } \\
\text { (Skilled } \\
\text { and non } \\
\text { skilled) }\end{array}$ & $\begin{array}{c}\text { Operator } \\
\text { (Machine) }\end{array}$ & $\begin{array}{c}\text { Project } \\
\text { Manager/ } \\
\text { Engineer }\end{array}$ & Total \\
\hline Non-Responses & 5 & 5 & 5 & 15 & 33.33 & 33.33 & 33.33 & 100 \\
\hline
\end{tabular}


Table 3: Specific Result

\begin{tabular}{|c|c|c|}
\hline $\begin{array}{l}\text { Psychotropic drug } \\
\text { types }\end{array}$ & Results or Findings & Effects or Implications \\
\hline Caffeine & $93 \%$ take it for alertness and for hyperactive. & $\begin{array}{l}\text { Irritability lethargy, headache, toxicity, excess daytime } \\
\text { sleepiness etc. }\end{array}$ \\
\hline Marijuana & $93 \%$ take it to acquire energy. & Mental ill health, excess daytime sleepiness etc. \\
\hline Tramadol & $85 \%$ to resist pain. & Lead to peptic ulcer etc. \\
\hline Codeine & $73 \%$ take it for the purpose of hyperactivity. & $\begin{array}{l}\text { Constipation where use for long time and convulsion may } \\
\text { occur, mental functions, acute pancreases, acute } \\
\text { intoxication etc. }\end{array}$ \\
\hline Alcohol & $57 \%$ take it for the purpose of work. & Diabetic and hypertension etc. \\
\hline
\end{tabular}

\section{CONCLUSION}

Psychotropic drugs and its consequences among construction workers cannot be ignored therefore, there is need to find ways to minimize the use of the substances by construction workers. This study appraised psychotropic drugs usage in Adamawa and its consequences on the construction workers (i.e. health and productivity effects or impacts) and types of psychotropic drugs being used. The result shows that majority of construction workers extensively consume and belief in the power of drugs for energy. Such drugs taken in greater quantities are caffeine, marijuana, tramadol, codeine, nicotine and alcohol. Further investigation shows that majority of them are addicted and want to discontinue in taking either of the psychotropic drugs because of ill health associated with drug taken and at times lead to very low productivity on site. Other side of psychotropic drug effect are; disobedient, quarreling and abnormal behaviours in the site [55and 56]

\section{RECOMMENDATION}

Every construction company must be concerned with the effects of psychotropic drugs and must provide management strategies for construction workers. These strategies could be proactive measure like training workload, adjustment, drug's effects identification, social structures and role classification [57]. Construction workers should undergo drug test process before given an employment, while seminars should be organized at least every quarter of the year on drug abuse or drug related issues or where special assistance in terms of professional advice and health intervention are given in accordance to [58, 59 and 60].

Site Engineers/Managers should encourage them to bring their challenges and problems forwards so that solution could be proffered instead of resorting to these dangerous drugs. There shall be collaboration between the construction firms and drugs regulatory agencies like National Drugs Law Enforcement Agency (NDLEA) need to step surveillance [61]

\section{REFERENCES}

[1] Goldenhar, M. L, Steven H., Moir, S., John, C. R . The "Goldlocks models" of two much, not two little, but just right, Journal of Safety Research 2003; 34(2), Pg. 215 26. 2003.

[2] Bowen P., Edwards P., Lingard H. and Cattle K. . "Workplace stress effects and coping mechanisms", ASCE Journal of Construction Engineering and Management [Online], 140(3) 2014 pp. 1-15. Available from: https://researchbank.rmit.ed.au/veiw/rmit:24657 [Accessed 05 January 2015]. 2014.

[3] Mclellan, A. T., Woody, G. E., and O'Brien,C. P. "Development of psychiatric Illness in drug abusers: possible role of drug preference." New Engl.J.Med.1979,301:1310-1314. 1979.

[4] Golaik, L. Kisten "American Journal of Pharmaceutical Education", 74 (10) Article S3 at cont. of American Association of Colleges Pharmacy Annual Report. 2010.

[5] Andrews, W and Harcourt, M. H. .Natural Mind: A revolutionary approach to the Drug problem revised edition. $\quad$ https://www.amazon.com/Natural-MindRevolutionary-approachupdated/dp/B0047TA4H0.ASIN:B0047TA4HO (Accessed on 8, Sept 2016) 2004.

[6] Sidney, H., and Kennedy , Psychotropic drugs: fast, facts, fourth edition. 1998.

[7] Tobias, Dianne and Charles ."General and Psychotropic indication use in construction industries".(NDLEA) Journal, Nigeria. 1997.

[8] Beal, D. L; Cohen, R. R., Durke, M. J., ."Cohesion and Performance in groups; a meta-analytic classification of construct relations." Journal of applied psycnet.apa.org. 2003.

[9] Ruppert, M. C .The Lies About Taliban Heroin. The wilderness publications,www.copyvcia.com 2001.

[10] Porthcourt, H. M., Pronunciation Guide at the way back machine - Arch. Dec. 23, Wikipedia free ency, publishing group, Hosten U.S.A. 2007.

[11] Mosby's Medical dictionary; 97803230854/US Elseview Health Bookshop, 9th Edition. 2009.

[12] Kosen, T. A and O'Conner, P .G.."Management of drug alcohol withdrawal". New 2003. Engl.J.Med.348:17861795.PUBMED 
[13] Andrew T. W. Health and Healing; The philosophy of integrative medicine and optimum Health Paperback 9,Dec. Barns and Noble book sellers Inc.112 fifth Avenue, New York .NY 10011, 2004.

[14] Srinivasan, V., Wielb, D. and Tebbet, I. R.. Analgesic effects of codeine-6-glucuronide after intravenous administration. European Journal of pain 1(3):18590doi:10.1016/S1090-380 (97)90103-8 PMID 15102399 1997.

[15] Oxford Dictionary of Sports Science and Medicine published 2007

[16] Nigeria psychiatric Association Journal 2009.

[17] Abudu,P. V. , Construction workers at risk. Published by the Nigeria's observer. 2005.

[18] Aluede,R. O., Peer group influence on human development. (NERA) unpublished. Articles 2002.

[19] Kent, Swedish charts on the single chart Wikipedia mobile Desktop. 2000.

[20] Anumonye, A. Drug use among construction workers in Lagos. UNODC-Bulletin on Narcotics. 1980.

[21] Bos, S. W.. Worker Drug and Other Substance Abuse in the construction industry. Baccalaurrus Scientlae Honores in construction management. Faculty of Engineering, the Built Environment and information Technology Nelson Mandela Metropolitan University 2015.

[22] Agar,M Dope Double Agent: Heroin double; the naked emperor on drug. Paperback7th,Feb.https://www.amazon.com/DopeDouble-Agent-Naked Emperor/dp/1411681037, 2007.

[23] Neptin, W . A. ,Substance Abuse in the Construction Industry. Unpublished PhD Thesis. Central Connecticut State University. 2005.

[24] Fax Lex Frieden."The needs of people with psychiatric disabilities during and after hurricanes Katrina and rita". Position paper and recommendations, National Council on Disability 133, F street, NW Suito850 Washington, DC 20004202-272. 2005.

[25] Kalix ,P. .Pharmacological properties of the stimulant khat. Pharmacol. Ther., ,48:397-416.PUBMED. 1990.

[27] Building and Construction Trades Department . AFL - CID $8^{\text {th }}-16^{\text {th }}$, suite 606 .Washington, D C , 202-347-1461, www.betcl.org., Journals Vol. IV.(Accessed on 2015) 2006.

[26] Mclellan, A. T, and Lewis, D. C ,O'Brien, C.P., and Kleber, H .D. Drug dependence a chronic medical illness: implications for treatment, insurance, and outcomes evaluation.JAMA,13:1689-1695. 2000.

[28] Brunton, L L., Lazo ,J.S. and Parker, K. L, Goodman and Gilman's the. Pharmacological Basis of Therapeutic, $11^{\text {th }}$ ed./editor. ISBN 0.07-142280-3, 2006. 1999.

[29] Dews, P. B., Curtis, G. L., Hanford, K. J., and O’Brien, C. P. The frequency of caffeine withdrawal in a populationbased survey and in a controlled, blinded pilot experiment. J. Clin.Pharmacol.33:1221-1232.PUBMED.

[30] National Agency for Food and Drug Administration and Control, Journals on the uses of caffeine 2001.

[31] Nnadozie, E. Good Health, NDLEA and Drug War in Nigeria. Unpublished Articles. 2004.
[32] Fernandes L. C. Kilicarslau, T., Kaplan, H. L., Tynddale, R. F., Sellers, E. M., Romach, M. K. ."Treatment of codeine dependence with inhibitors of cytochrome P4502D6". J. ClinPsychopharmacol 22(3) 326-9 doi:10:1097100004714-20020600000014,PMID12006901, 2002.

[33] World Anti-doping Agency, 2008

[34] Volkow, N., D., Wang ,G. J., Fowler, J.S., et al..Reinforcing effects of psychostimulants in humans are associated with increases in brain dopamine and occupancy of D2 receptors. J. Pharmacol. exp. Ther., 291:409-415. PUMED. 1999.

[35] Tramadol extended release (ER) for posttraumatic stress disorder ,Publication by Clinical Trials.gov.identifier (NCT Number). Ann Clin psychiatry, Aug: 26(3):217-21 https:clinicaltrials.gov/ct2/show/NCT01517711,Cincinn ati,Ohio,US 45220(Accessed,8/9/2016) 2014.

[36] American Psychiatric Association Benzodiazepine, Toxicity, and Abuse: A Task, Force Report of the American Psychiatric Association. APA, Washington. 1999.

[37] Graham, T. E and Spriet, L. L."Performance and metabolic responses to a high Caffeine does during prolonged exercise", published by US National Library of medicine and National Institute of Health, Dec. 7 1(6); 2292-8, PMP, 1778925 (Pubined-index for MEDLINE). 1991.

[38] Baselt ,R. .Disposition of toxic Drugs and Chemicals in man (8thed.).Foster city, CA .Biomedical publications pp353-360, 2008.

[39] Anderson, Dr. Burnham, K P; Thompson, W. L ."Null hypothesis testing: problems, prevalence and alternative journal of wild life management", Vol. 64, No. 4 (Oct. ), PP. 912-923. Published by Allah Press, Stable URL:http://www.jstor.org/stable/3803199(Accessed 14,0ct2008/2:35.), 2000.

[40] History of codeine.-Narconon .www.narconon.org/druginformation/codeine-history.html (Accessed on 5,Sept 2016), 2004.

[41] Psychotropic drug, facts and information ,Encyclopedia of Espionage, Intelligence, and Security/2004/Sassoon, Judyth www.encyclopedia.com/topic/pschotropic.drugs.aspx (Ac cessed on 5,Sept2016), 2004.

[42] Perry, P. J , Alender, B. , DeVane, C. L. and Liskow, B. I. ,Psychotropic Drugs Hand Book .Lippinlot Williams and Wilkins

ISBN13:9780781762731,10:078176273:https://www.amazon.com/ psychotropic drug-handbook-paulperry/dp/0781762731(Accessed on March. 7, 2006). 2006.

[43] Benowitz N. L., Portchet, H., Sheiner, and Jacob, .P. III Nicotine absorption and cardiovascular effects with smokeless tobacco use: Comparison with cigarettes and nicotine gum .Clin.Pharmacol.Ther.,1988, 44:2328.PUBMED. 1988

[44] Winerman, L. Breaking free from addiction. Monitor staff, Vol. 44 No. Print Version: page 30 www.apa.org/monitor/2013/06/addiction.aspx. 2013

[45] Srivastava, E. D., Russel, M. A., Feyerabend ,E.C., et al Sensitivity and tolerance to nicotine in smokers and nonsmokers .Psychopharmacology , 105:63-68.PUBMED. 1991. 
[46] Rojascorrales, M. 0; Rahola, G, Tramadol induces antistimulant type effects in mice, Life Sciences. Elsevier. 1998.

[47] Kreek, M. J. Laforge, K. S.,and Butelman, E ,Pharmacotherapy of addictions. Nature Rev. Grug Discov.1:710-726. 2002.

[48] Joy, J .E. Watson, S. J., Benson, J. A. Institute of Medicine .Marijuana and Medicine: Assessing the Science Base .National Academy Press, Washington. 1999.

[49] Volkow, N. D ,Epigenetic of Nicotine: nail in the coughing science translational medicine. - stm.sciencesmag.org. 2011.

[50] United State National Institute of Health 2011.

[51] UNODC; Types of Drugs International Control [Online] 2007, Vienna; UNODC. Available from: http://www.unodc.org/pdf/26 june0709/typesofdrugsbrochure-en.pdf [Accessed 28, Dec. 2014], 2007

[52] Oshiokoya,0. "Perception of drug abuse amongst Nigeria workers," Published by World Journal of Medical Science. 2006.

[53] Agar, M , Dope Double Agent: The Naked Emperor on drugs ISBN (13), 97815411681033, published on Feb.7 by Lulu Press, Inc. (Lulu.com). 2007.

[54] Iversen, L. . Cannabis and the brains. Brain, 126:12521270.PUBMED. (2003)

[55] World Health Organization Department of Metal Health and Substance Abuse Global Status Report on Alcohol, Geneva: WHO. 2004.
[56] Gordon, Verhoef and Krause ; "Curbing Crime and Violence on Construction Sites". Specifier, June 2014 p.4, 2014.

[57] NHGH; “An Employer's Guide to Workplace Substance Abuse: Strategies and Treatment Recommendations."Slavit, W.L., Reagin, A. and Finch R.A. Available from: https://www.businessgrouphealth.org/pub/f31519572354-d714-5191-c11a80a07294 [Accessed 6 April 2014] 2009.

[58] MICCS "MICCS, Substance Abuse Program," Available from:

http://www.miccs.org/storage/miccs\%20template.pdf [Access 26 March, 2014], 2006.

[59] Thirteen. wnet;" Substance Abuse Prevention in the Workplace an Employers Guide"s [Online]. Available from:

https://www.thirteen.org/closetohome/pdf/CTHemploy er.pdf, 1998 (Accessed 05 January, 2015). 1998.

[60] Construction Labour Relations Association of British Columbia and Bargaining Council of British Columbia Building Trade Unions. Construction Industry of British Columbia Substance Abuse Testing and Treatment Program Policy. Vancouver: British Columbia 2008.

[61] Adeyemi, V. 0. "An assessment on the use of psychotropic drugs on construction workers in Adamawa" .Unpublished undergraduate degree thesis: Department of Building, Modibbo Adama University of Technology, Yola

2011.

\section{APPENDIX A}

Table 3Psychotropic Drugs uses among construction workers analysis.

\begin{tabular}{|c|c|c|c|}
\hline & Questions & Responses & Percentage \\
\hline \multirow[t]{3}{*}{ Q1: } & Do you take drugs while or during construction work? & & \\
\hline & Yes & 35 & 85 \\
\hline & No & 6 & 15 \\
\hline \multirow[t]{3}{*}{ Q2: } & $\begin{array}{l}\text { Do you gain more energy from drugs, when you are carrying out } \\
\text { construction work? }\end{array}$ & & \\
\hline & Yes & 30 & 73 \\
\hline & No & 11 & 27 \\
\hline \multirow[t]{3}{*}{ Q3: } & $\begin{array}{l}\text { Do you work for a long time on site when you take drug? } \\
\text { Yes }\end{array}$ & & \\
\hline & No & 37 & 90 \\
\hline & & 4 & 10 \\
\hline \multirow[t]{4}{*}{ Q4: } & How many hours can you work on site when you take drugs? & & \\
\hline & i) $\quad 6$ hours & 10 & 24 \\
\hline & 8 hours & 20 & 49 \\
\hline & iii) $\quad 11$ hours & 11 & 27 \\
\hline \multirow[t]{3}{*}{ Q5: } & Do you easily get tired when you are on site while on drugs? & & \\
\hline & Yes & 11 & 27 \\
\hline & No & 30 & 73 \\
\hline \multirow[t]{3}{*}{ Q6: } & $\begin{array}{l}\text { Sometimes when on drugs, do you really understand the } \\
\text { specification of what material you are asked to use? }\end{array}$ & & \\
\hline & Yes & 38 & 93 \\
\hline & No & 3 & 7 \\
\hline \multirow[t]{3}{*}{ Q7: } & How many blocks can you lay in a day if you take drugs? & & \\
\hline & Yes & 39 & 95 \\
\hline & No & 2 & 5 \\
\hline \multirow[t]{3}{*}{ Q8: } & Do you use any kind of drugs as long as it will give you energy" & & \\
\hline & Yes & 30 & 73 \\
\hline & No & 11 & 27 \\
\hline
\end{tabular}


\begin{tabular}{ll}
\hline Q9: & Do you think that it is proper to take drugs for construction work? \\
Yes
\end{tabular}

No

$6 \quad 15$

Q10: Do you take caffeine for construction work?

Yes

No 38

$38 \quad 93$

$3 \quad 7$

Q11: $\quad$ Do you take nicotine (tobacco) for construction work?

Yes

No

No response

$6 \quad 15$

$30 \quad 73$

$5 \quad 12$

Q12: Do you take tramadol hydrochloride for construction work?

Yes

No

Q13: Do you take marijuana (cannabis) for carrying out construction

$6 \quad 15$
work?

Yes

No

(1)

Q14: Do you take pentazocine injection for carrying out construction work?

Yes

No

No response

6

Do you take heroine for carrying out construction work?

Yes

No $\quad 5$

No response

Q16: Do you take cocaine or any kind of drug that contain codeine for carrying out construction work? Yes No

Q17: Do you take alcohol for carrying out construction work?

Yes

No

No response

Q18: $\quad$ Can you reduce or stop taking all the psychotropic drugs because of the effect on your health?

Yes 